\title{
Gamma-Volantis on BEXUS 28: From the first sketch to the launch campaign
}

\author{
Elisabeth Berka \\ Institute of Aerospace Engineering \\ Technische Universität Dresden \\ Dresden, Germany \\ gamma-volantis@star-dresden.de
}

\author{
Nils Hensch \\ Institute of Aerospace Engineering \\ Technische Universität Dresden \\ Dresden, Germany
}

\begin{abstract}
It is hard for students to get hands-on experience in the field of aeronautics and to apply knowledge learned in university to actual projects, since space missions are complex, expensive, and take a long time to complete. Therefore, a group of students at the Technische Universität Dresden (TU Dresden) formed the group "Studentische Arbeitsgruppe Raumfahrt Dresden" (STAR Dresden), which focuses on giving students from different study fields the chance to work on space related activities, by taking part in various competitions and student projects, and even hosting events in Dresden.
\end{abstract}

Currently, STAR Dresden is participating in the Balloon Experiment for University Students (BEXUS), which is organised by the German Aerospace Centre (DLR), the Swedish National Space Agency (SNSA) and the European Space Agency (ESA). One of the teams selected for BEXUS cycle 12 is Gamma-Volantis, which is implementing a setup for experimental ozone and humidity sensors developed by TU Dresden's Institute of Aerospace Engineering (ILR).

The balloon flight carrying the experiment will take place in October. Until then, the students will be able to work on subsystems typical for space flight missions and will learn how to write a Student Experiment Document (SED). This document is the scientific documentation of the experiment. They will also gather experience of presenting their work, giving presentations in front of the BEXUS board during design reviews such as the preliminary design review (PDR) and the critical design review (CDR), and even in front of potential sponsors. Due to the tight schedule provided by the launch date, the students will also have to learn to cooperate and communicate between the different subsystem teams, and to be organized in order to achieve the desired goal.

This paper will present the Gamma-Volantis experiment and the methods used by the students to acquire further knowledge and experience on space flight missions. It will contain the difficulties arising from the experiment's requirements and the given circumstances under which the project is supposed to operate. The paper will also discuss the different approaches used by the students to solve the problems and how they interact with different parties such as the BEXUS experts or other student teams from Europe. Overall it will summarize the lessons learned by the students and how they expanded their knowledge during the BEXUS project.
Keywords-STAR, TU Dresden, Gamma-Volantis, BEXUS, student participation

\section{INTRODUCTION}

To make space engineering more tangible for themselves, students at the Technische Universität Dresden (TU Dresden) formed the group "Studentische Arbeitsgruppe Raumfahrt Dresden" (STAR Dresden) [1]. This group takes part in different competitions and projects with a main emphasis on aerospace engineering. Gamma-Volantis is one of STAR Dresden's latest projects accepted to REXUS/BEXUS. The REXUS/BEXUS programme is realised under a bilateral Agency Agreement between the German Aerospace Center (DLR) and the Swedish National Space Agency (SNSA). The Swedish share of the payload has been made available to students from other European countries through the collaboration with the European Space Agency (ESA). Experts from DLR, SSC, ZARM and ESA provide technical support to the student teams throughout the project. EuroLaunch, the cooperation between the Esrange Space Center of SSC and the Mobile Rocket Base (MORABA) of DLR, is responsible for the campaign management and operations of the launch vehicles [2].

Gamma-Volantis will launch on the BEXUS balloon 28 in October. The experiment's mission objective is to field test and verify the performance of experimental ozone sensors and air humidity sensors developed by the Institute of Aerospace Engineering (ILR) at TU Dresden. According to the BEXUS cycle 12 schedule the students must go through different stages in developing their experiment until it is ready to launch.

\section{EXPERIMENT SETUP}

To collect atmospheric data, the GAMMA-VOLANTIS experiment consists of two sensor units and a data processing unit. A sensor unit is made up of 7 different sensors (i.e. experimental ozone sensor with gold electrodes, experimental ozone sensor with platinum electrodes, reference ozone sensor, pressure sensor, experimental air humidity sensor, reference air humidity sensor, temperature sensor) as shown in Fig. 1. The second sensor unit is for redundancy. Both units are mounted to the outer wall of the experiment facing the outside of the gondola for easy access to the atmosphere. 


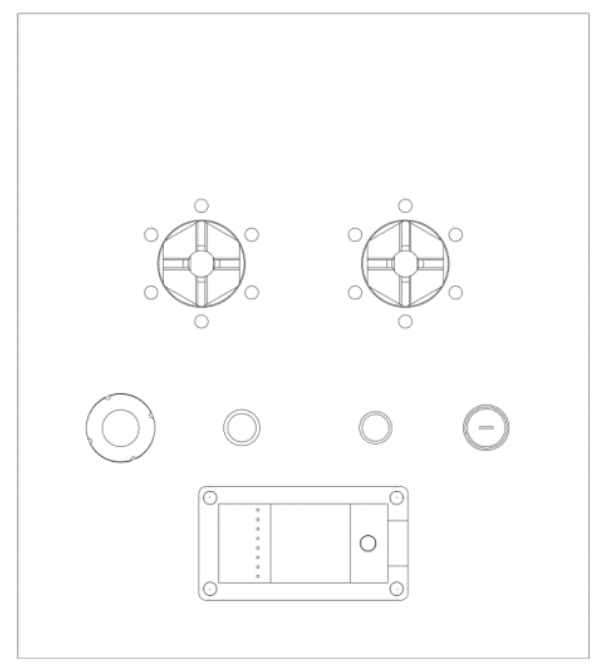

Fig. 1. Sensor unit (Top: Experimental Ozone Sensors; Middle: Pressure, Temperatur, Reference Air Humidity, Experimental Air Humidity Sensor; Bottom: Reference Ozone Sensor)

The experimental ozone sensors developed by the ILR are solid-state electrolyte sensors. Compared to common ozone sensors, they are smaller, faster, inexpensive, and consist of no moving parts. The electrolyte material needs to be humidified to maintain its ionic conductivity, so it is counteracting the crosssensitivity shown in many other miniaturized ozone sensors. The air humidity sensor provided by the ILR is a new, simple, and low-cost sensor with fast response times.

\section{Challenges \& Solutions}

During the design and assembly phase, the team members encountered many problems that can be assigned to some of the subsystems of the mission:

- Project Management

- Electrical Power System

- Thermal Control System and Structure and Mechanism

- Command and Data Handling Systems

\section{A. Project Management}

The mission schedule given by the REXUS/BEXUS organizers includes due dates for reviews (i.e. Preliminary Design Review (PDR), Critical Design Review (CDR), Integration Progress Review (IPR), Experiment Acceptance Review (EAR)) as well as the launch date. Some of the due dates were during exam periods when the students had to concentrate on their studies and working on the experiment became a secondary concern.

Another vital part of the experiment's success is frequent communication between the subsystems because changes in one subsystem can greatly affect others and require major changes in the overall design. Since the team had just formed and the team members did not know each other well, communication was poor and not every member was up-to-date.

For time management, the experts from the REXUS/BEXUS programme suggested the use of a Gantt chart, where a detailed project schedule could be illustrated. This chart was very useful in seeing whether the team was on time or had a delay. By planning the schedule, the students had to take time periods with low productivity, such as the exam periods, into account and work around them.

To increase the team's communication and avoid misunderstanding, the students scheduled weekly meetings and met outside of the university for a barbeque or a game night. This built a strong group cohesion and improved the conversation and information flow between the subsystem groups.

\section{B. Electrical Power System}

A major problem with the electrical power system was the missing electrical engineering expertise. The Gamma-Volantis team mainly consists of mechanical engineering students with only basic knowledge in electrical engineering. This lack of knowledge posed a challenge in designing the electronics, particularly considering the experiment's main objectives hugely rely on electronics, as with most space applications. Especially unifying high current power electronics, sensitive analogue circuits and digital data transmission on a single circuit board, all working at very low temperatures, represented a major challenge.

Another difficulty came from the readout electronics provided by the institute because the modification and adaption to the experiment's specific needs required more work and time than expected.

After strictly zoning the circuit board, multiple iterations, and a careful component selection, the students managed to design a functioning, compact circuit board with the help from the institute and through extensive research and testing.

\section{Thermal Control System \& Structure and Mechanism}

The experimental ozone sensors need to be humidified and therefore require a small water reservoir. In the stratospheric atmosphere, the water would freeze and cause the experiment to fail. This problem is why the students had to find a way of keeping the water reservoir at a constant temperature above freezing point. Another main problem was to keep the electronics in their working temperature range and to keep the temperature stable to decrease the risk of failure. The electronics also needed to be properly shielded from electromagnetic interference, as the ozone sensors work with very small currents.

The ozone sensor already had a temperature sensor inside the water reservoir to monitor the temperature during flight. To regulate the heat, heating foils were attached to the outside of the reservoirs with a heat resistant glue [3]. The sensor housing is shown in Fig. 2. 


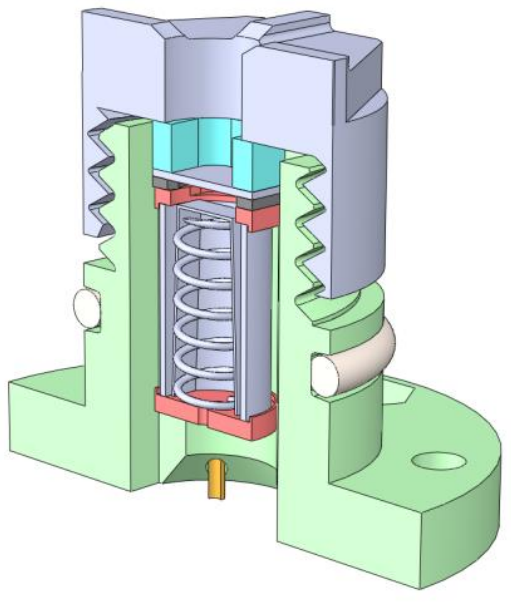

Fig. 2. Sensor housing of the experimental ozone sensor

To maintain the temperature inside the box at a constant level, the box is covered in polyethylene foam and reflecting foil to lower solar radiation. The sensor units facing outside the gondola have an additional polyethylene panel mounted in front of them in order to protect the sensors from the sun as well.

The electronics are stored in a smaller aluminium box inside the experiment to shield the electronic components from said interference. Fig. 3 shows a model of the Gamma-Volantis experiment with the aluminium box inside.

Throughout the process of calculating the heat flux and load distribution inside the experiment, the students greatly increased their knowledge of handling simulation software. They also acquired experience in choosing suitable materials and designing a project that is easy to manufacture and easy to use.

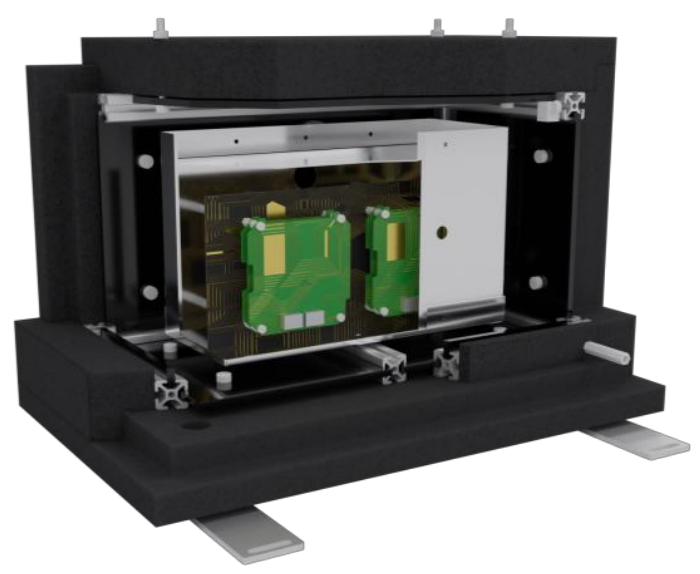

Fig. 3. Section view of the Gamma-Volantis Model

\section{Command and Data Handling Systems}

Programming code in a group can be challenging without the proper tools. In the beginning, the team members shared their latest progress via ZIP files, which made it hard to keep everyone up-to-date or go back to older versions if an error occurred.

After some time, the team started to use GitLab, a web-based DevOps lifecycle tool, which includes a version management system [4]. GitLab combines versions from each programmer with access and combines them, making the current code available for everyone. This hugely increased the workflow and improved the team's work.

\section{CONCLUSION}

For a young university group such as STAR Dresden, REXUS/BEXUS has been and continues to be a great project to get started in aerospace engineering and give hands-on experience to students. The Gamma-Volantis team members had the chance to get a first glimpse of the typical space project procedures and learned new techniques for problem solving with the help of different experts. The team also presented the experiment's progress to a review board.

For future projects, the team agreed having an experienced student as team leader may increase the communication within the group and might support younger students who are new to the project. It might also be a benefit to include different engineering students with different qualifications, e.g. electrical engineering, since acquiring knowledge in a different area of expertise is time consuming.

\section{OUTLOOK}

After the Gamma-Volantis experiment is completed and accepted at the Integration Progress Review, it will be shipped to the Kiruna Launch Pad in Sweden, where it will launch on the BEXUS balloon 28 in October. After the flight, acquired data will be analysed and shared with the institute. The team members will continue to work on future aerospace projects and share their experience and knowledge with younger students.

\section{ACKNOWLEDGMENT}

The entire Gamma-Volantis team would like to thank Tilman Schüler and Yves Bärtling from the ILR at TU Dresden for their constant support and advice during the project. The team also acknowledges the excellent support from the all the entities involved with REXUS/BEXUS, i.e. DLR, SNSA, ESA, ZARM, and MORABA.

\section{REFERENCES}

[1] STAR Dresden, STAR Dresden - "About Us" page (available at https://star-dresden.de/wir/?lang=en; accessed 15 August 2019)

[2] REXUS/BEXUS - "Home" page (available at http://rexusbexus.net/; accessed 15 August 2019)

[3] Hensch, N.: „Entwurf und Test eines Gehäuses zur Integration neuartiger Ozonsensoren mit integrierter Befeuchtung". Forschungspraktukum. TU Dresden, 2019.

[4] GitLab - "Home" page (available at https://about.gitlab.com/; accessed 15 August 2019 